\title{
Shallow Netroots: Hypertext Links to Advocacy Organizations in Political Blogs
}

\section{Mark A. Leccese, Emerson College, USA}

\begin{abstract}
In 2002, a Weblog author coined the term "netroots" - a combination of the words "Internet" and "grassroots" - to describe the use of political blogs as a tool to spur political activism and political organization. This study gathered data to determine how frequently the top three progressive and the top three conservative blogs use hypertext links to direct their readers to the Web sites of political advocacy organizations. The study coded 2,087 hypertext links on these six influential political blogs for seven consecutive days in January 2008, during the presidential primaries, to determine what percentage of hypertext links took readers to advocacy organizations. Only $5.7 \%(n=119)$ of links on these blogs directed readers to political advocacy Web sites.Although there may be a netroots phenomenon, it has manifested itself not in political blogs, but in the Web sites and mass e-mail and texting lists of the candidates and their campaign operations.
\end{abstract}

Keywords: Politics, blogging, US politics, political communication 


\section{Introduction}

Previous studies and survey research about the internet's effect on political participation have found users who visit political Web sites and blogs are more likely to vote in elections, donate money to candidates and volunteer on campaigns (Gil de Zúñiga, Veenstra, Vraga, Shah, 2010;Lewis 2010;Forrester \&Matusitz, 2010; Shah, Cho, Eveland, Kwak, 2005).There has beenlittle study, however, of whether the producers of web content — particularly political bloggers - encourage readers to participate in political activity.Beginning in 2004, when the internet played an important role in the presidential campaign of Howard Dean (Wolf, 2004), journalists and bloggers on the left have made many claims that a loose confederation of political blogs and other politically oriented Web sites have created a powerful new force in American politics that has been given the name "netroots."By studying one aspect of the online behavior of political bloggers - their use of hypertext links — we can begin to assess these claims. ${ }^{1}$

The most influential blogs — and thus leaders in the purported netroots movement - are those that receive the most visitors.Hyperlinks are precisely what creates this hierarchy of blogs (Hindman, 2009, p. 18).Research on networks has further shown that popular blogs become increasingly popular.The Web has been described as "a complex, overlapping, evershifting set of individuals who have organized themselves into groups of every sort" (Weinberger, 2002, p. 108).Hypertext links, by their nature as ties between Web sites and the people who create and maintain them, are a key component in building social systems.Tracking which blogs are most frequently linked to by other blogs makes it clear which blogs are most influential.Two physicists researching the behavior of networks such as the Web have demonstrated that linking among Web sites conforms to a power law distribution, a "rich-get-richer" occurrence in which older nodes of a network receive far more incoming hypertext links than newer nodes (Barabasi\& Albert, 1999).Hindman (2009, p. 53) confirmed the existence of a power law distribution among political websites.The blogger Bowers (2007) refers to this as the "short head/long tail" phenomenon ("The Way It Was," para. 12).Roughly $1 \%$ of left-wing political blogs receive more than $95 \%$ of all leftwing blog traffic (the "short head"), while the remaining 99\% of left-wing political blogs receive less than $5 \%$ of all left-wing blog visits (the "long tail").The netroots is a relatively new phenomenon and its definition remains imprecise. 
Feld and Wilcox (2008) defined netroots as citizen activists "using the Internet to gather information, to organize with other like-minded folks across the country, to plan events, to raise money, and to make the case for the candidate" (p. 36).Chait (2007) offered a more narrow definition of netroots: "a subset of the liberal blogs, constituting those blogs that are directly involved in political activism, often urging their readers to volunteer for, or donate money to, Democratic candidates" (p. 20).Farrell (2009) defined netroots as a wide and informal network of political bloggers, activists, organizers and fund-raisers who support the Democratic Party and Democratic candidates and do their political work using the Web rather than the traditional persuasive and organizational tools offered by the mainstream media, the telephone and face-to-face interaction (p. 36).

On Election Day in 2006, as the Democratic Party gained majorities in the U.S. House and U.S. Senate for the first time since 1994, soon-to-be Senate Majority Leader Harry Reid wrote in a post on the blog Daily Kos: "Without the netroots, Democrats would not be in the position we are in today.It is as simple as that" ("You Got Us Here" Reid, 2006, para. 6).Reid's statement is just one of the many claims for the power of the netroots - a combination of the words "Internet" and "grassroots" - to recruit campaign volunteers, spread the campaign's message and raise campaign funds.According to Davis (2009), since 2004, when supporters of the campaigns of Democratic presidential candidates Wesley Clark and Howard Dean used the Internet and blogs to boost their candidates into contention in the 2004 Democratic presidential primaries, bloggers, who comprise the core of the netroots, have claimed "incessantly" (p. 7) they have changed politics.

We can begin to examine the claims made by scholars, bloggers and journalists about the influence of the netroots by studying hyperlinking patterns of non-traditional media political blogs, specifically at whatrate a sample of heavily trafficked blogs use links to direct their readers to organizations that advocate or raise campaign funding for candidates or political parties.

The format of a blog gives bloggers multiple ways to politically influence readers: text, video, audio, images, and hypertext links, which the blogger inserts to direct readers to other web sites.Hypertext links are an important difference between blogs and traditional communications media, including one-to-one communication and one-to-many 
communication.Hypertext links bring web blogs together in a way that demonstrates the priorities and agendas of the Web sites' authors. That is the purpose of hypertext links in a political blog: to direct readers' attention to what the blog writer believes provide credible or important sources of information (Turow\&Tsui, 2008, p. 21).More than 90 percent of the political blogs studied by Davis (2009, pp. 77-78) provided hypertext links in their posts.Davis writes: "Links don't just provide news and commentary to the reader; they often do so in a manner designed to reinforce" the political agenda of the blogger.Embedding a Web site with links communicates to the reader that the messages in the text and the messages to be found in following the links are dependent upon one another.This is a "profound psychological consequence" (Sundar, Kalyanaraman\& Brown, 2003, p. 48).

In an experimental study of how hyperlinking patterns of campaign Web sites affect readers' perception of candidates, researchers found the number of hyperlinks provided correlated with positive perceptions of candidates (Williams, Trammel, Postelnico, Landreville\& Martin, 2005, p. 179).Hyperlinks stand out from the other text on a page and increase the user's ability to control the information-seeking process, and the decision about what links to include is an exercise of online gatekeeping authority (Dimitrova, Connolly-Ahern, Williams, Kaid\& Reid, 2003, p. 403-404).

Previous research on the hypertext linking patterns of political blogs found that the authors primarily link within their own political persuasion, and that political blogs rely heavily and link with a high rate of frequency to - online mainstream media outlets for the information on which the bloggers then comment.A study of blog posts during the 2004 election found that more than nine in ten links on progressive blogs link to other progressive blogs, and roughly the same number of links on conservative blogs directs the reader to other conservative blogs (Adamic\& Glance, 2005, p. 4).

Reese et al. (2007) argue "the 'blogosphere' recalls the public sphere idea of Habermas, a provocative if elusive way to think about the social 'geography' of publiccommunication" (p. 237).Other scholars, however, look at studies of linking among political blogs and see the opposite of Habermas' public sphere.Sunstein (2007) discusses the concept of what he calls "enclave deliberation," (p. 77) in which political discourse on the Internet remains insulated among groups of like-minded people.The result is the loss of shared experience in political 
discourse leading to society as a whole to share fewer common reference points in our debates about politics and public policy (p. 106).Keen (2007) takes an even bleaker view: "Blogs on both the left and right have perfected the art of political extremism" (p. 3).

Winship (2006), author of The Democratic Strategist blog, attempted to make a rough calculation of the number of people participating in the Democratic netroots movement using a data set from a Pew Internet \& American Life survey (2005). One perfect of adults told Pew they regularly get news or information from political blogs, and Winshipcalculated that number to equal 2.24 million voters, which he writes makes the netroots "a force to be reckoned with" ("How Influential Is The Netroots? or, You Want Links?" para. 7).Kerbel (2009) wrote that by 2006 the netroots was "a movement with teeth (p. 62)," and to demonstrate the netroots power he compiled a set of metrics he argues proves the influence of the netroots in the 2006 federal election cycle, including more than two dozen additional contested Congressional seats in 2006 than 2004; a significant increase over the same period in small-amount donor contributions; and growth in the number of campaigns that "converged" online fund-raising and a web presence with a "high profile" on independent political blogs (pp. 87).

Few political commentators have made more fervent claims for netroots than progressive bloggers and Democratic Party activists Armstrong and Zuniga (2006).The web, they argued, allows people across the country to organize powerful movements behind candidates and issues. The two wrote that millions of Web users were already involved in netroots organizing and that blog readers could grow to 25 million from 20 million by 2010 (p. 176).

We can investigate the assertion that political blogs played an important role in the netroots movement in one week of the 2008 presidential primary season by examining the linking patterns of six top political blogs to determine how frequently these blogs use links to direct readers to the Web sites of political advocacy organizations. We can also use the data to examine how frequently links in these blogs do not direct readers to the Web sites of political advocacy organizations - and to what kind of Web sites those links direct readers instead. 


\section{Method}

The first step in identifying the six most influential political blogs was to use four different online blog-ranking services to determine which independent political blogs were most influential, based on a combination of daily visitors to each blog and the number of Web sites that link to each political blog (known as "links in").Four blog-ranking services were consulted on January 8, 2008:

- Nielsen BuzzMetrics’ BlogPulse (http://www.blogpulse.com/08_01_07/topWeblogGroup.html), which ranks by daily links in;

- Blogrolling.com Hot 500 (no longer available; accessed on January 7, 2008), which also ranks by daily links in;

- Technorati.com (http://technorati.com/pop/blogs/), which ranks by a six-month rolling average of links in;

- The Truth Laid Bear Blogosphere Ecosystem (http://truthlaidbear.com/ecosystem.php), which ranks by daily visits.

Fifteen political blogs appeared in the top 10 of at least one of the blog-ranking services.To create the list of the three most influential progressive blogs and the three most influential conservative blogs, the top political blog on each site was ranked 1, the second was ranked 2, and so on.Among the four tracking sites, 13 political blogs appeared at or near the top in the rankings and were included in these calculations.Each of those blogs was assigned a score of 14-n for each tracking service where $n$ equals the rank, so that the top-ranked blog on each blog-ranking Web site received 13 points, the second-ranked blog 12 points and so on.The average of the scores from the four blog ranking systems was calculated and a 1 to 13 overall ranking was created based on the averages.The results appear in Table 1. 


\begin{tabular}{|c|c|c|c|c|c|}
\hline Blog & BlogPulse & Technorati & TLB ECO & Blogrolling & Total \\
\hline Daily Kos & 13 & 12 & 13 & 12 & 50 \\
\hline Michelle Malkin & 10 & 8 & 10 & 10 & 38 \\
\hline InstaPundit & 6 & 6 & 12 & 13 & 37 \\
\hline Talking Points Memo & 11 & 9 & & 11 & 31 \\
\hline Crooks and Liars & 9 & 10 & 11 & & 30 \\
\hline \multicolumn{6}{|l|}{ The Corner at the } \\
\hline National Review & 12 & 7 & & & 19 \\
\hline Think Progress & 8 & 1 & & & 19 \\
\hline Power Line & & & 7 & 9 & 16 \\
\hline Wonkette & & & 8 & 7 & 15 \\
\hline Huffington Post & & 13 & & & 13 \\
\hline Huge Hewitt & & & 6 & 5 & 11 \\
\hline Eschaton & & & 9 & & 9 \\
\hline Atrios & & & & 8 & 8 \\
\hline Volokh Conspiracy & & & & & 7 \\
\hline Rightwingnews & & & & 6 & 6 \\
\hline
\end{tabular}

The Corner at The National Review blog was eliminated because it is not independent — it is owned and operated by a traditional media organization, The National Review magazine.This study sought to track three blogs that are considered progressive and three that are considered conservative (see "Politico.com's Map of the Blogosphere" at http://www.politico.com/blogosphere/), even though the netroots is largely a phenomenon of the Democratic Party, to gain the most inclusive data set and to get a clearer picture of how the top political blogs use hypertext links to direct their readers to political advocacy organizations. To achieve that balance, Power Line was substituted for Think Progress

\section{Top Six Political Blogs}

- Daily Kos (http://www.dailykos.com/)

- Michelle Malkin (http://michellemalkin.com/)

- InstaPundit (http://www.instapundit.com/)

- Talking Points Memo (http://www.talkingpointsmemo.com/)

- Crooks and Liars (http://www.crooksandliars.com/)

- Power Line (http://www.powerlineblog.com/) 
All the examined links on these six political blogs were followed and coded to determine the number of total links that led the reader to an advocacy organization Web site, with advocacy organization defined as any Web site, including blogs, of a candidate or a partisan fundraising group, “watchdog” group or single-issue group, in addition to other partisan groups.

Links that did not lead the reader to the Web site of an advocacy organization were coded into four categories:

1. Mainstream media: Any Web site run by a newspaper, TV network, radio network, wire service or magazine that employs salaried staff reporters and whose Web site is a supplement to its print editions, broadcasts or news service.

2. Other blogs: Any independent Web site in the form of a weblog that has as its primary focus politics, public affairs or government.

3. Internal: A link that directs a reader to another page, usually from a previous day, on the same blog.

4. Primary sources: Web sites of government agencies; think tank reports; academic journals; and for-profit businesses. Links to businesses (e.g., a book listing on www.amazon.com) were coded as "primary source" since a business Web site serves as a primary source for summary information on a commercial product, such as a book.

The study coded all links in the posts on the front pages of the six top political blogs in the U.S.(excluding permalinks andblogrolls) over seven consecutive days - Thursday, January 10, 2008 to Wednesday, January 16, 2008 — during the beginning of the 2008 presidential primary season, when bloggers would be particularly active and a comprehensive sample of blog postings could be collected.If a link was to a video on www.youtube.com, the video and the posting details were examined to determine if any advocacy organization posted it.

The total number of links coded was 2,087, with 1,180 links on progressive blogs and 907 links on conservative blogs coded.Links to advocacy organizations were summarized by category as number $(\mathrm{N})$, percent (Pct) and 95\% confidence interval (CI). The 95\% CI was calculated and the comparison between progressive and conservative blogs was undertaken to account for the clustering within the seven posting days and six blogs using an over-dispersed binomial model that inflates the standard errors. 
As a check on the coding, the six blogs were randomly sampled without replacement to be coded by a second coder on one of the seven days in the studied time frame.This assumes that the ability to categorize links on the days on which each blog was double-coded was representative of the studied time frame. So the linking patterns of a blog on a particular day may not have been representative, the coders assume the ability to code the links was not affected.If Scott's pi for intercoder agreement was above 0.75 , the data gathering would continue; if it was below 0.75 , the data gathering would cease and begin again at a later time with more extensive training for the second coder.The second coder categorized 78 links.Scott's pi determined an intercoder agreement of 0.808 , so the data gathering continued.

\section{Results}

Table 2 summarizes the coding of the 2,087 links found on the main page of each blog, including the total number of links to advocacy organization.Only 5.7\% (95\% CI 4.2-7.7\%) of links were to advocacy organizations.

Table 2

\begin{tabular}{|c|c|c|c|c|}
\hline & \multicolumn{2}{|c|}{ Total } & \multicolumn{2}{|c|}{ Advocacy Organizations } \\
\hline & $\mathrm{N}$ (links) & $\mathrm{N}$ (links) & Pct. & $95 \% \mathrm{Cl}$ \\
\hline Progressive Blogs & 1180 & 100 & $8.5 \%$ & $6.3 \%-11.3 \%$ \\
\hline Conservative Blogs & 907 & 19 & $2.1 \%$ & $1.1 \%-3.9 \%$ \\
\hline Total & 2087 & 119 & $5.7 \%$ & $4.2 \%-7.7 \%$ \\
\hline
\end{tabular}

The blog Daily Kos, founded and operated by MarkosMoulitsasZuniga, linked to advocacy organizations far more $(n=71 ; 11.5 \%)$ than any of the six blogs studied, with Crooks \& Liars linking to advocacy organizations 28 times (8.1\%).No other blog linked to advocacy organizations more than six times.On the progressive blogs, only about half $(n=52)$ of the 100 links to the websites of advocacy organizations were links to Web sites of candidates, fundraising groups, voter registration organizations or political parties. 
Table 3

Links to Advocacy Organizations by Blog and Category

\begin{tabular}{|c|c|c|c|c|c|c|c|}
\hline & $\mathrm{N}$ (Inks) & Pct. & Candidate & Fundraising & $\begin{array}{l}\text { Voter } \\
\text { Registration }\end{array}$ & $\begin{array}{l}\text { Political } \\
\text { Party }\end{array}$ & Other \\
\hline $\begin{array}{l}\text { PHOGRESSIVE } \\
\text { Daily Kos }\end{array}$ & 71 & $11.5 \%$ & 22 & 19 & 1 & 1 & 28 \\
\hline Crooks \& Lars & 28 & $8.1 \%$ & 4 & 3 & 1 & 0 & 20 \\
\hline Talking Points Memo & 1 & $1.8 \%$ & 1 & 0 & 0 & 0 & 0 \\
\hline Total Progresssive & 100 & & 27 & 22 & 2 & 1 & 48 \\
\hline $\begin{array}{l}\text { Pet. Of All Links } \\
n=1,180\end{array}$ & $8.47 \%$ & & $2.28 \%$ & $1.86 \%$ & $0.02 \%$ & $0.01 \%$ & $4.06 \%$ \\
\hline CONSERVATIVE & $N$ (Inks) & Pct. & Candidate & Fundraising & $\begin{array}{l}\text { Voter } \\
\text { Registration }\end{array}$ & $\begin{array}{l}\text { Political } \\
\text { Party }\end{array}$ & Other \\
\hline InstaPundit & 6 & $1.3 \%$ & 3 & 0 & 0 & 0 & 3 \\
\hline Michele Malkin & 6 & $1.9 \%$ & 0 & 0 & 0 & 0 & 6 \\
\hline Power line & 5 & $3.6 \%$ & 1 & 0 & 0 & 0 & 4 \\
\hline Total Conservative & 19 & & 4 & 0 & 0 & 0 & 13 \\
\hline $\begin{array}{l}\text { Pct. Of All Links } \\
n=907\end{array}$ & $1.87 \%$ & & $0.44 \%$ & $0.00 \%$ & $0.00 \%$ & $0.00 \%$ & $1.43 \%$ \\
\hline
\end{tabular}

Political blogs linked to mainstream media Web sites with double the frequency they linked to Web sites in any other category.Almost half - 46.5\% (95\% CI 43.8\%-49.2\%) — of the links coded went to mainstream media Web sites, twice as many links as took the reader to any other category and eight times as frequently as bloggers linked to the Web sites of advocacy organizations. The next highest linking rate was to other independent blogs, at $23.0 \%$ (95\% CI $18.8 \%-27.8 \%)$, followed by links to internal pages of the blog (15.0\% - 95\% CI 11.7\%$19.1 \%)$ and primary source Web sites $(9.8 \%$ - 8.2\%-11.7\%)

Table 4

\section{All Links by Category}

\begin{tabular}{|c|c|c|c|}
\hline & $\begin{array}{l}\mathrm{N} \\
\text { (links) }\end{array}$ & $\mathrm{Pct}$. & $95 \% \mathrm{C}$ \\
\hline Advocacy O'ganizaticn & 119 & $5.7 \%$ & $4.2 \%-7.7 \%$ \\
\hline Mansiream Merlia & 970 & $46.5 \%$ & $43.8 \%-492 \%$ \\
\hline Other Independen: Blogs & 480 & $23.0 \%$ & $18.8 \%-27.8 \%$ \\
\hline internal & 311 & $15.0 \%$ & $11.7 \%-19.1 \%$ \\
\hline $\begin{array}{l}\text { Primary Source } \\
\eta=2,087\end{array}$ & 204 & $9.8 \%$ & c. $2 \%-11.7 \%$ \\
\hline
\end{tabular}

\section{Discussion}

Whatever role the top political blogs play in the netroots movement, this analysis of their hypertext linking patterns makes it clear they seldom play the role many have claimed for them: urging their readers, by using links to direct them to candidates of fund-raising Web 
sites, to get directly involved in political campaigns by volunteering or donating. A study by Wallsten (2008) of 10,000 political blog posts found that more than 95 percent of the posts studied were opinion or information and not efforts to spur political participation."Political bloggers place less emphasis on directly influencing the institutionalized political process than they do on changing the prevailing political discourse," Wallsten wrote (p. 32).

Political blogs may help drive the netroots movement in ways other than the traditional political grassroots function of convincing voters to volunteer for and donate to campaigns, at least in the use of their hypertext links.Perhaps political blogs' most important function is to disseminate a form a partisan propaganda.Sunstein (2007) wrote, "What we know about both links and individual behavior supports the general view that many people are mostly hearing more and louder echoes of their own voices" (p. 55).Davis (2005) argued the goal of many bloggers is "expression and reinforcement, not interaction and exchange" (p. 124).

If netroots, as the neologism implies, is supposed to resemble traditional grassroots organizing, political office-seekers and their campaigns have recognized it and moved with alacrity and sophistication to assert control over the fruits of the netroots movement.In a 1999 book, Davis wrote: "At each innovation in the history of mass communications, existing media and other actors adapted to the new technologies and incorporated them. Rather than losing power, they retained it" (p. 30). That appears to be the case with electronic communication.

Although Obama, as president, has maintained an alliance with political bloggers, it is a wary alliance.A Washington journalist reported in 2009 that Obama not only did not rely on bloggers for political help, he did not like or trust them.Instead, the White House created its own netroots movement, including blogs, from scratch (Farrell, 2009, p. 35).

What has happened since the rise of netroots, in the 2004 election cycle, is manifest in both the vast number of voters who participated in Obama's campaign through his campaign wesbite and President Obama's distain for bloggers.Candidates' Web sites have assumed the functions that were, in early days on the netroots, the province of bloggers.Candidates' Web sites have become "a virtual home for online supporters" and a "vehicle for fund-raising, message disseminationand voter mobilization" with a plethora of links (Kerbel, 2009, pp. 
138-139). Where the 2004 presidential campaign of Howard Dean, generally recognized as one of the key events in the emergence of netroots, was driven by bloggers and such independent Web sites as Meetup.org, by 2008 the Obama campaign's website used links to drive readers to events organized and run by the campaign itself "so that the campaign could keep track of what people were doing" (Kerbel, 2009, p. 140). When he took office, according to one newspaper report, President Obama retained a database from his campaign of information of 13 million Americans who signed to receive electronic news from his campaign.Of that 13 million - about $19 \%$ of the 67 million American who voted for Obama - electronically participating in the Obama campaign, 3.1 million Americans contributed a total of $\$ 700$ million to the campaign (Bleifuss, 2009, p. H-1). Carpenter (2010) wrote that the Obama campaign's use of the internet "revolutionized the key elements of a modern U.S. political campaign" and dubbed the campaign's use of the internet "the Obamachine." (p. 224)

The research cited above suggests that although bloggers see themselves at the center of the netroots, political campaigns and elected officials have quickly adopted the technology — and the reach - of the Web, e-mail, and instant messaging.Campaigns are now the driving force of the netroots movement not, as this study's data show, political bloggers. The netroots movement, birthed by bloggers, has been taken over by political professionals.

The results of this study of one aspect of the behavior of the most influential independent political bloggers - hypertext linking patterns — suggest bloggers are more interested in commenting on politics than encouraging readers to participate in political activity by directing them to the web sites of advocacy organization with links, which indicates, along with researchby others on the use ofthe internet by political candidates, that netroots isnot the potent tool in American electoral politics its promoters claim.

\section{Limitations and Future Studies}

This study chose as its sample six of the most heavily trafficked and widely read political blogs.A random sample of a similar number of blogs may have produced different results, but given that hyperlinking patterns in networks such as the blogosphere follow a power law distribution (Barabasi\& Albert, 1999), examining the most heavily linked-to and trafficked blogs allows this study to gather data on blogs that are opinion leaders and serve other 
bloggers as exemplars of how a blog should be organized and written. The power law distribution also suggests that a more robust sample would have produced similar data.

Future studies may want to examine a larger sample size over a longer period of time, or may want to conduct ethnographic or survey research among political bloggers and blog readers to determine ifand how, specifically, political blogs spur their readers to political activism, making campaign contributions, and voting.Data for link click-through rates in political blogs is proprietary and was thus unavailable for this study.Survey research querying political bloggers about which links in their blogs receive the most click-throughs could be a fruitful inquiry for future studies.

This study also does not address the occurrence or effects of Web-based political organizing outside the United States, and a comparative study would be a fruitful area of study. 


\section{References}

Adamic, L.,\&Glance, N. (2005). The political blogosphere and the 2004 U.S. election: divided they blog. Retrieved March 7, 2012 from https://docs.google.com/viewer?a=v\&q=cache:0z7PstUv8cJ:citeseerx.ist.psu.edu/viewdoc/download?doi\%3D10.1.1.59.9009\%26rep\%3Dr ep1\%26type\%3Dpdf+The+political+blogosphere+and+the+2004+U.S.+election:+divi ded+they+blog\&hl=en\&gl=us\&pid=bl\&srcid=ADGEESjuvRr9R-BQDsJvLN0ECzwSxwDpS1kWymBNqkURyD6WbKGDcKPGO5rScWdtTHRqZntQ_HRmhQejn XxPs9-vlWO1yPddELgFgJHeZZrFq3yguGc0M1NYePe4M1tTHPa1KDshYG\&sig=AHIEtbQ9u7YqRLeacrxgjE32SxkVSqijdA

Armstrong, J., \& Zuniga, M.M. (2006).Crashing the gate: Netroots, grassroots, and the rise of people-powered politics. White River Junction, VT: Chelsea Green Publishing Company.

Barabasi, A.-L., \&Albert., R. (1999). Emergence of scaling in random networks.Science(5439), 509-511. DOI: 10.1126/science.286.5439.509

Belifuss, J. (2009). Obama's online army: It could help set the new president's agenda, mobilize support for his proposals and diminish the influence of entrenched Washington interest groups.The Pittsburgh Post-Gazette. Retrieved March 7, 2012 from http://www.post-gazette.com/pg/09025/944085-109.stm?cmpid=news.xml

Bowers, C. (2007, July 8). New establishment rising? The end of the flat blogosphere.Retrieved March 7, 2012 from http://www.openleft.com/showDiary.do?diaryId=13

Carpenter, C. A. (2010). The Obamachine: Technopolitics 2.0. Journal of Information Technology \& Politics, 7(2/3), 216-225. DOI: 10.1080/19331681003765887.

Chait, J. (2007, May 7). The left's new machine.The New Republic, 236.

Davis, R. (1999). The Web of politics: The internet's impact on the American political system. New York, NY: Oxford University Press.

Davis, R. (2005). Politics online: Blogs, chatrooms, and discussion groups in American democracy. New York, NY: Routledge.

Davis, R. (2009). Typing Politics: The Role of Blogs In American Politics. Oxford: Oxford University Press.

Dimitrova, D., Connolly-Ahern, C., Williams, A.P., Kaid, L.L.,\&Reid, A. (2003). Hyperlinking as gatekeeping: online newspaper coverage of the execution of an 
American terrorist. Journalism Studies, 4(3), 401-414. DOI: 10.1080/14616700306488

Farrell, H. (2006). Can the netroots reshape American democracy? Boston Review, 31.

Farrell, H. (2009, July-August). Do the netroots matter?The American Prospect, 20.

Feld, L., \& Wilcox, N.(2008).Netroots rising: How a citizen army of bloggers and online activists is changing American politics. Santa Barbara, CA: Praeger Publishers.

Forrester, M. M., \&Matusitz, J. J. (2010). A narrowing digital divide: the impact of the Internet on youth political participation. Communicare, 29(2), 85-98. Retrieved from EBSCOhost.

Gil de Zúñiga, H., Veenstra, A., Vraga, E, \& Shah, D. (2010).“Digital democracy:

Reimagining pathways to political participation," Journal of Information Technology \& Politics, 7:1, 36- 51.DOI: 10.1080/19331680903316742

Hindman, M. (2009).The myth of digital democracy. Princeton, NJ: Princeton University Press.

Keen, A. (2007).The Cult of the Amateur: How Today's Internet is Killing Our Culture. NY: Doubleday.

Kerbel, M. R. (2009). Netroots: Online progressives and the transformation of American politics. Boulder, CO: Paradigm.

Lewis, M. (2010).A hierarchical regression analysis of the relationship between blog reading, online political activity, and voting during the 2008 presidential campaign.(Doctoral dissertation.Retrieved from ProQuestDissertations \& Theses database.Document No. 3451989).

Raine, L., Horrigan, J., \&Cornfeld, M. (2005).The internet and campaign 2004. Washington, DC: Pew Internet \& American Life Project. Retrieved March 6, 2012 from http://www.pewinternet.org/Reports/2005/The-Internet-and-Campaign-2004.aspx

Reese, S. D., Rutigliano, L., Kideuk, H., \&Jaekwan, J. (2007).Mapping the blogosphere: Professional and citizen-based media in the global news arena.Journalism8, 235-261. DOI: $10.1177 / 1464884907076459$

Reid, H. (2006, Nov. 7). You got us here. Retrieved March 7, 2012 from http://www.dailykos.com/story/2006/11/7/115739/853

Shah, D. V., Cho, J., Eveland Jr., W. P, \&Kwak, N. (2005). Information and expression in a digital age: Modeling internet effects on civic participation. Communication Research, 32(5), 531-565. Retrieved from EBSCOhost. DOI: 10.1177/0093650205279209

Smith, A. (2011). The internet and campaign 2010. Washington, DC: Pew Internet 
\&American Life Project. Retrieved March 6, 2012 from

http://pewinternet.org/Reports/2011/The-Internet-and-Campaign-2010.aspx

Sundar, S. S., Kalyanaraman, S., \&Brown, J. (2003). Explicating web site interactivity : Impression formation effects in political campaign sites. Communication Research, 30(1), 30-59. DOI: 10.1177/0093650202239025

Sunstein, C. (2007). Republic 2.0. Princeton, NJ: Princeton University Press.

Turow, J., \&Tsui L.(2008). Preface to Part I. In Turow, J., (Ed.) \&Tsui L., The hyperlinked society: Questioning connections in the digital age (pp. 21-23). Ann Arbor, MI: The University of Michigan Press.

Wallsten, K. (2008). Political blogs: Transmission belts, soapboxes, mobilizers, or conversation starters? Journal of Information Technology \& Politics, 4(3), 19-40. DOI: $10.1080 / 19331680801915033$.

Weinberger, D. (2002). Small pieces loosely joined: A unified theory of the web. New York, NY: Perseus Books Group.

Williams, P., Trammel, K. D., Postelnico, M.,Landreville, K.D., \&Martin, J.D. (2005). Blogging and hyperlinking: use of the web to enhance viability during the 2004 US campaign. Journalism Studies, 6(2), 177-186. DOI:10.1080/14616700500057262

Winship, T. (2006, July 11). How influential is the netroots? or, you want links?Retrieved March 7, 2012 from http://www.thedemocraticstrategist.org/strategist/2006/07/how_influential_is_the_netr oot.php

Wolf, G. (2004). How the internet invented Howard Dean. Wired, 12:01. Retrieved March 7, 2012 from http://www.wired.com/wired/archive/12.01/dean.html. 